\title{
Creating an Industrial Setting in an Engineering Lab
}

\author{
Jim Devaprasad, Ray Adams, Paul Duesing, \\ David McDonald, Morrie Walworth \\ Lake Superior State University
}

\begin{abstract}
Engineering schools across the nation have worked diligently to develop capstone courses to provide undergraduate senior students a smooth transition from university to industry. In addition to this capstone experience, engineering students could be introduced to the expectations of industry earlier in their curriculum. An understanding of the industrial environment is provided to Lake Superior State University (LSSU) students in the junior year through some of the engineering lab courses. An overall goal in these courses is to entail the critical thinking skills of the students to solve problems through open-ended lab assignments that are not completely defined. A project will be given to the student (the project engineer) from the faculty (the project manager) in the form of an industrial memo. The timelines and minimum expected outcomes of the project will be defined in the memo. Completion of the project satisfying only the minimum outcomes is considered average performance thereby encouraging students to explore other considerations and outcomes for a superior evaluation. Both objective and subjective measures are used for student evaluation.
\end{abstract}

Other aspects of this method of instruction involves development and use of industry type communication skills and team skills. Students are initially apprehensive of the industrial setting in the lab but become self-sufficient and independent as the semester progresses. As the faculty take the approach of a busy project manager, there is less time spent in supervising and guiding of students in the lab particularly during the latter half of the semester. This method of instruction has been implemented in the lab component of several engineering and engineering technology courses at LSSU. Apart from describing the unique features of this instructional strategy, the paper presents two examples of projects used in two junior level engineering lab courses.

\section{Introduction}

In recent years, there has been considerable discussion and dialog regarding the competency gaps of graduating engineers that need to be filled by educational institutions ${ }^{1}$. Several professional organizations and similar groups have sought input from engineers and managers from industry to determine the skills that employers demand of graduating engineers ${ }^{2-4}$. The results of these studies show that competency gaps in graduates usually fall under the following categories: communication skills, teamwork and interpersonal skills, creative problem solving skills, and leadership ${ }^{5}$. In general, these skills have been referred to as soft skills. 
Engineering educators across the country have responded to address the competency gaps by making changes to the engineering curriculum and the content of courses. A major activity in this direction has been in the development of capstone senior design projects courses where issues related to soft skills are addressed ${ }^{6}$. These courses serve the role of providing students a smooth transition from university to industry.

Students are better prepared for the senior projects experience, if they are exposed to the soft skills requirements earlier in the curriculum ${ }^{7,8}$. This could be done in the lab component of the junior year courses. In these lab courses, an understanding of the industrial environment can be provided to the students by incorporating soft skills requirements in a simulated industrial setting. At LSSU an industrial setting is established in some of the lab sections of the junior level engineering courses to particularly emphasize the importance of communications skills and teamwork.

The following sections discuss the background on the engineering education at LSSU, why lab sections lend themselves well for implementation of an industrial setting, the industrial setting, how to implement the industrial setting, issues related to communication and team skills, the grading methodology, and faculty and team responsibilities. Also included are two example projects.

\section{Background}

Lake Superior State University (LSSU) is a state university in Michigan with approximately 300 students in the engineering and engineering technology programs supported by 13 faculty. The programs with the significant enrollments are Mechanical Engineering, Electrical Engineering, Computer Engineering, and Manufacturing Engineering Technology. A major mission of these programs is on preparing graduates to work in industry by providing a mix of theory and application with strong emphasis on applied engineering.

LSSU is on a semester system that is 15 weeks long (14 weeks of study and one exam week). Most of the engineering and engineering technology courses at LSSU have lab sections associated with them. A typical engineering course will consist of two to three lecture hours per week with two to three lab hours. Upon graduation, over $95 \%$ of the students work in industries as engineers, typically, in a manufacturing setting. Therefore, the faculty are constantly looking to using industrial manufacturing practices in the courses, particularly in the junior and senior years. The senior projects course sequence at LSSU involves multi-disciplinary student teams working on projects solicited from industry. In the junior year, the lab projects of some of the courses are designed to enhance the student's communication and team/interpersonal skills. 


\section{Lab Sections for Implementing an Industrial Setting}

A good place to create an industrial setting is in the laboratory sessions of engineering courses. The integration of soft skills in the lecture class is more difficult because of the amount of technical material that needs to be covered. Exercises in the lecture hours involving written communications, oral communications, and teamwork involve large amounts of time making it difficult to integrate with the lecture topics. In the lab meetings, however, such exercises can be included for the following reasons:

- Lab sections typically have fewer students than in a lecture section.

- Lab projects usually involve equipment and hence it is more convenient to simulate an industrial manufacturing setting.

- There is a larger amount of time in a lab sessions for students to work on their soft skills. A 50 minute lecture class is a very short time to do assignments on teamwork and oral presentations.

- It is easier to build soft skills exercises around the technical projects required to be completed by the students in the lab.

- Since lab exercises involve equipment and people (lab technicians), there are unexpected problems that arise such as equipment breakdown and lack of immediate access to resources. This helps in furthering the "what-if" situations that typically arise in the real world of manufacturing.

For the reasons mentioned above the lab sessions of a few engineering courses can be chosen to implement an industrial setting.

\section{The Industrial Setting}

The first element in implementing an industrial setting in an engineering lab is to determine an appropriate name and logo for the simulated manufacturing company (housed in the lab). Thus, a lab can no longer be referred to as a "lab". Instead, the company name is used for all forms of communications. For example, a manufacturing process lab can be called Precision Manufacturing Inc.

The naming of the company and the development of a company logo could be a part of the first assignment given to students broken up into teams of 2 to 4 students. Students are very creative and innovative in developing names and logos! A simple voting process can be used to choose the name and the accompanying logo to be adopted in the course. Once determined, the company name and logo are used in all future written communications and in overheads for oral presentations.

A personnel structure that would work for the industrial setting (the newly formed company in the lab) should be simple and could be as follows:

- The students are project engineers in a division of the company and could be assigned tasks working either as individuals or in teams. 
- The faculty member, teaching the lab sections, plays the role of the project manager of a division.

- There are several divisions in the company and the project managers or division leaders report to a company executive committee consisting of the president and vice-presidents.

This is a sufficient structure upon which the more important issues such as communications skills and team skills can be built.

\section{Implementation of the Industrial Setting}

The first time a student encounters a course where an industrial setting is implemented in the lab, he/she is unsure of what the expectations are and how their performance is going to be evaluated. The reason for this is because they typically come from an environment where the expectations and performance measures are clearly outlined in the individual lab assignments. For example a lab assignment in a previous course could have walked the students through the various steps that need to be completed to finish the lab with points for each step (for a grade) and perhaps for a required report. As a result of the concerns that exist initially, it would be necessary to transition the students from a traditional lab setting to the one presented in this paper. Also, for the first part of the lab course, it may be necessary for students to learn technical skills the traditional way before they are ready to perform as project engineers in the company (formed for the lab).

In the transition process, during the first part of the course, students are given assignments (individually or as small teams), where the objective is to develop basic technical knowledge in the subject matter of the engineering lab. The assignments are specific and the outcomes expected are clearly defined. For example, in a robotics lab, an initial objective could be that the students gain familiarity with the programming languages of the robots in the lab. The traditional setting applies at this juncture, that is, the student is the learner and the faculty is the expert. There is considerable guidance from faculty through brief lectures, handouts, and problem solving sessions.

As the semester progresses, the projects are less specific and more open ended. A problem faced by the company (the company formed for the lab) will be presented to the project engineers (the students) by the project manager (the faculty). The project engineers as part of small teams (usually two or three members) use the resources available to them to find solutions to the problem . The resources include the company facilities, the documentation on equipment, product and process, and the project manager (to a much lesser extent than before). The projects are designed so that a reasonable outcome can be reached within the specified amount of lab time. The analysis and presentation of the experimentation with recommendations require time away from the company equipment area (the lab). The mid-semester projects are usually designed to be two weeks long to give the project engineers a chance to return to the experimentation area during the second week for further analysis and to explore results beyond the minimum expected outcomes. 
During the last part of the semester, a more challenging company problem is assigned involving bigger teams with a duration of at least three weeks. Some basic guidelines are provided to each of the teams on issues such as team norms and expectations, timelines, and scheduling of meetings. This is to facilitate better communication between the members and to encourage equal participation of the members.

\section{Communication Skills}

An industry-type format, that is easy to comprehend and to the point, is used for the communications between the students (project engineers) and the faculty member (project manager). This format consists of a two component structure, namely the EXECUTIVE SUMMARY and the DISCUSSION.

The executive summary keeps in mind that the company executive is interested in the bottom line and does not have the time to read all the details. It has three parts: the organizational problem (OP) which briefly outlines the problem assigned, the technical tasks (TT) which provides information on what was done to address the problem, and the rhetorical purpose (RP) which gives the conclusions and the recommendations. The executive summary is sometimes referred to as the industrial memo.

The discussion component provides more detail on the OP, TT and RP. The discussion component is written to a technical audience who are interested in the specifics such as equipment used, mathematical and engineering analysis, and drawings and graphs. The introduction section of the discussion component should forecast the contents of the discussion. Information provided on issues should flow from general to specific using an effective formatting scheme. Any computer program submitted with the discussion component should be written in a modular fashion (using a subroutine structure) and well documented for easy interpretation.

During the implementation of the industrial setting, it is important that the two component structure be followed. Even in situations such as when a team needs to request extra time on an equipment, an industrial memo is expected. The use of e-mail is allowed but the format should be adhered to. Not all project outcomes, as reported by a team, need to have a discussion component. Further the length of the discussion component, when required, can vary from one page to ten pages depending on the scope of the project.

The emphasis on the oral communication is placed more on the communications amongst team members and with the project manager. When a solution to a problem is being presented to the project manager, the team members need to clearly communicate and illustrate the methodology used and the rational for arriving at a solution. Every team member is expected to participate in this meeting with the project manager. During this meeting, several questions will be raised by the project manager on issues including: was a what-if analysis conducted, were safety and ethics considered, and was efficiency/optimization of methods completed. The what-if analysis considers changes in the constrains and conditions of the project along with corrective measures needed. This analysis along with the safety, ethical, and efficiency considerations contribute to 
the teams grade beyond the $\mathrm{C}$ level. This is an exercise for the team members' critical thinking and problem solving skills.

When team members schedule meetings amongst themselves, the time, date and place information on the meetings is provided to the project manager at least two days in advance. The project manager could partake in the meetings to provide input and to observe the communications taking place amongst the members.

If time permits, an oral presentation on the outcomes and solutions of the last project by the teams can be scheduled. In this situation, the project engineers can be given information (handouts) by the project manager on how to structure the presentation. The presentation with any demonstrations can be given to all project teams (in the class), the project manager, and any other invited guests (other faculty who could play the role of company executives).

\section{Team and Interpersonal Skills}

The importance of working in teams, an attribute demanded by industry, is emphasized throughout the semester. The composition of the teams is usually determined by the project manager. Small teams of 2 to 3 members are used in projects for most of the semester except for the final project where there could be 4 to 6 members in a team.

The teams are provided with instruction and are encouraged to go through a simple exercise where the team norms and expectations are determined by the team members. This particularly applies to the final project. The teams are expected to have simple timelines established for their project implementation process with the names of the individuals responsible for implementing the project components identified. This information in provided to the project manager in the form of an industrial memo. Teams are encouraged to have several meetings, at least one of which is attended by the project manager. A schedule of all the team members and the project manager is made available for the teams.

The project engineers begin to realize the difficulty in scheduling meeting times that is convenient for everyone concerned (an industrial setting). Further, they also realize the importance of scheduling meetings well ahead of time and avoid procrastination. In addition to time related issues, the project engineers also get a taste of personality issues and its effect on project outcomes. They begin to realize that it is essential to accommodate and work with individuals with different personalities for successful completion of the project. There is also the understanding of the different roles that team members play such as leaders, followers, performers, and slackers.

Due to time limitations there is little instruction provided to the students on team dynamics. But, if an objective of the course is to bring an awareness to the students on real issues of being part of a team, then this structure would accomplish that. 


\section{Evaluations/Grading Methodology}

The concept of objective grading versus subjective grading is introduced to the students in the implementation of an industrial setting in the lab. Previously, the students are used to a highly structured learning and working environment at the university. Most courses and labs have clear directions on how the students will be evaluated using exams, quizzes, homework, written assignments, and lab projects. In industry, the evaluation process is not as clear and is composed of both subjective and objective methodologies. In other words, employer expectations of an engineer may not be similar to faculty expectations of an engineering student.

Unlike other courses, a student's performance in the simulated industrial lab settings will be judged using subjective and objective measures. The combination of these measures will account for the final grade. Points towards a grade are assigned for a variety of activities that include successful completion of projects, written exercises, oral exercises, and interpersonal skills. These activities could be either team or individually based. The evaluation of the student performances in some of these exercises is subjective. To further emphasize the subjective nature of industry type evaluation, a certain percentage of the final lab grade is purely subjective.

As an example, if the total lab points is 100 , the breakdown of these points could be as follows:

- successful completion of projects assigned 50 points

- written assignments (memos and discussions) 15 points

- presentation/demonstration of projects 10 points

- overall subjective evaluation 15 points

The subjective evaluation is used to reward teams and team members when they produce results beyond the minimum expected outcomes. In addition, the subjective evaluation also reflects on an individual's interpersonal skills. At the end of the semester, each student gets a letter grade for the lab as in other traditional courses.

\section{Faculty and Team Responsibility}

The roles played by faculty (the project manager) and team members (the project engineers) change as the semester progresses. During the first part of the semester, the faculty member has the responsibility of teaching the technical fundamentals for the engineering lab course. The students are expected to learn and understand the technical fundamentals so that they have the necessary background to solve the industry like problems that will be presented to them.

When the implementation of the industrial setting occurs, the students and the faculty disassociate themselves from the typical learner-teacher paradigm. Given below are some points on the faculty member's role:

- The faculty as project manager plays the role of a busy administrator who is not closely involved with the project like the project engineers.

- The project manager is not a technical expert in the project. He/she relies on the expertise of the project engineers. 
- The project manager will attend at least one meeting of each of the project teams

- The project manager is interested in the success of the project and other real issues such as reliability, safety, breakdown of equipment, efficiency, and optimization.

- By using objective and subjective measures, the team and the individual team members will be evaluated on their technical and soft skills performances.

- The faculty need to treat the students as professionals involved as project engineers in a company.

- Completion and presentation of the minimum requirements of the project without considering what-if conditions, safety issues, ethical concerns, reliability, efficient methodology, and optimization issues would result in an average performance evaluation (a $\mathrm{C}$ grade).

- Projects should be completed by the due date. If delays for project completion cannot be validated (such as equipment failure) then it affects the team's performance evaluation in both the objective and subjective measures.

- The teams have only one opportunity to present and demonstrate their completed project to the project manager.

The responsibilities of the teams and the project engineers (students) in the teams are as follows:

- The project engineers are the experts on the technical issues and cannot be interrupting the project manager whenever a questions arises (during the lab sessions too!)

- The project manager should be approached with a concern only after the team has taken every feasible step to solve the problem. For example, if a question arises on a new programming command in a robot programming language, the team should first make a full attempt to figure out the use of the command by reading the user's manual.

- If a minor equipment or other related problems arise, the teams are responsible for getting the problem fixed after getting approval from the project manager.

- The teams need to schedule regular meetings and notify meeting place and times to the project manager in advance.

- All requests and relevant communications should follow the industrial memo format.

\section{Sample Projects}

Two examples of problems that serve as projects for the industrial setting in the lab are presented. Both examples are projects assigned to students during the second half of the semester and have a two week time frame for completion.

\section{Example Project 1:}

The first example, given below, is from a junior level course taken by Mechanical Engineering and Electrical Engineering students in the Robotics and Control Systems option. The course, titled RS385 Robotics Engineering, is a 3 credit hour course that meets weekly; 2 hours for lecture and 3 hours for lab. The problem is assigned to student teams with each team consisting of two individuals. Given the two week time frame, each team has 6 hours of lab time at the equipment with 12 hours of work expected outside of this lab time. 
AAT

\title{
ADVANCED AUTOMATION TECHNOLOGIES
}

\author{
To: $\quad$ xxxxxx, Robotics Project Engineer \\ From: Jim Devaprasad, Project Manager \\ Date: $\quad$ February 6, 1997
}

Subject: Repalletization of beer bottles at a Colorado bottling plant.

\begin{abstract}
Advanced Automation Technologies (AAT) has undertaken (as a subcontract) a robot programming assignment for a beer manufacturing company in Colorado. As your next assignment we would like you to write AML code for IBM (7545/47 or 7535) robots to unload 6-packs of beer bottles ( $3 \times 2$ configuration) and repalletize them as 8-packs them for shipping. More information on the project as provided by the manufacturing engineer at the Colorado plant is provided below.
\end{abstract}

As a new sales promotion, the company is interested in repackaging the beer into an 8-pack configuration (basically a $3 \times 3$ configuration without a part in the center). The beer bottles in the $3 \times 2$ configuration (6packs) arrive from two bottling stations. They enter the robot workstation on two input conveyors. The presence of the 6-packs on the conveyors at the robot workstation is indicated by proximity sensors. The beer bottles must be repackaged in the 8-pack configuration on an output conveyor.

A problem in the Colorado plant is the age of the input and output conveyors. It has been necessary to do preventive maintenance work on these conveyors every three months. This leads to positioning problems of the 6-packs on the input conveyors and the 8-pack on the output conveyor. Every time a preventive maintenance is done on the conveyors, the location of the bottles on the 6-packs and on the 8-pack in relation to the robot is expected to change. It is therefore imperative that the number of taught robot points be kept a minimum to re-commission the robot quickly

Before your robot code is sent to the manufacturing engineer at the Colorado plant, it is recommended that a simulation of the repalletization task be done in house at AAT using our IBM robots. Please submit your AML code in disk format, with a memo attached, to run a demonstration of the simulation (**during your lab session the week of February $17 * *$ ). Please make sure that the documentation submitted by you is clear so that another robotics engineer at AAT can run your simulation on the appropriate IBM robot. In your memo, clearly indicate any assumptions used and recommendations on the implementation of your robot code.

The robotics lab at LSSU has multiple robot stations with work envelopes that have hardware to simulate input conveyors and output conveyors. In addition, these stations are provided with input/output communication boxes that simulate input/output communications to and from the robot with external devices.

The objective of this project is for students to learn the following: the concepts of robotics palletization, programming the robot using palletization commands, and soft skills to function effectively in teams. The minimum expected outcome is the task of repalletization beer bottles from a 6-pack configuration to an 8-pack configuration. The open-ended nature of the project, where additional work is necessary involving critical thinking skills, is incorporated into the 
project as noted in the third paragraph of the memo. The expected deliverables on completion of the project is elaborated in the last paragraph.

\section{Example Project 2:}

The second example, given below, is also from a junior level course taken by Manufacturing Engineering Technology and Mechanical Engineering (Design Option) students. The course, titled Programmable Logic Controllers, is a 3 credit hour course that meets weekly; 2 hours for lecture and 2 hours for lab. The problem is assigned to student teams with each team consisting of four individuals. Given the two week time frame, each team has 4 hours of lab time at the equipment with 8 hours of work expected outside of this lab time.

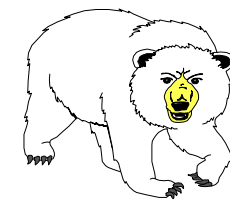

\section{POLAR \\ BEAR \\ PARK}

Polar Bear Park)

To:

Merry Holiday, Chief Systems Engineer (Your Boss at

From: $\quad$ Chris Maas, Vice President Operations

Subject: $\quad$ Traffic Congestion

As a result of Polar Bear's marketing and improved attractions, traffic in the park has increased dramatically. This traffic increase has caused congestion at the main north-south and east-west intersection in the center of the park. Please have one of your automatic controls engineers (ACE) install a smart traffic light at this intersection. The detailed operation of the light is up to you and your engineering staff. However, it should incorporate a day versus night operating mode due to the reduced traffic after 10:00 p.m. Please have the ACE send me a memo that summarizes the results of the installation, the cost and the operations of the new light.

\section{RS365 PROGRAMMABLE LOGIC CONTROLLERS}

\section{INDUSTRIAL SITUATION AND MEMO}

You have been called to your bosses' office for a meeting regarding the letter from Mr. Maas (See Polar Bear Memo). In the meeting you discussed the operations of the traffic light. The sequence listed below was determined as adequate to meet the operational needs of the park.

After the design is completed, Merry Holiday requested that you hold a design review with the supervisor of maintenance and herself. Merry also requested that she be copied on the memo to Chris Maas. Finally, she specified that the maintenance department needs to receive an instruction manual that covers operation and set up of the PLC controlled traffic light. 


\section{BACKGROUND/SEQUENCE}

1. Traffic light is situated at a standard intersection of the north-south and east-west roads. North-south is the secondary road.

2. There are no requirements for special turning lanes.

3. The standard time for a green and red light combination is 120 seconds.

4. The standard time for a yellow light is 15 seconds.

5. When the light is in the automatic mode, it should function in the following ways:

a. If no traffic is present on the secondary highway (north-south), the system should keep a green light on for the main highway (east-west), and a red light for the secondary highway.

b. If traffic is present on the secondary road, the light should go through a standard sequence of red, green, yellow, etc.

c. There should be a 5 second period of red lights for both directions between red to green transitions.

d. If it is night time, (timer sensed) the lights for east-west should blink yellow and the north-south blink red. Night time starts at 2200 hours and ends at 0600 hours. The blinking time is 1.5 seconds for on and off.

e. If a north-south vehicle is at the intersection when the transition to night mode occurs, the sequence must be completed prior to switching to the night mode.

6. The system is not in the automatic mode, the lights for east-west should blink yellow and the northsouth should blink red. The blinking time period is 1.5 seconds for on and off.

7. When the system is first turned on, it blinks yellow for east-west and blinks red for north-south. This should continue until the system is put in the automatic mode.

8. If power fails and is restored, the light should start with the blinking yellow for the main road and blinking red for the secondary road.

9. The system must have separate counters that keep track of the vehicles going north/south, east/west, and the total vehicles passing the intersection.

10. The MicroView is to be used to set the time (with the key pad) and to view the traffic counts.

The programmable logic controller (PLC) lab at LSSU has multiple stations. Each station includes two types of programmable logic controllers that have push button and toggle switches connected to the inputs. The lab equipment also includes two operating systems which are a "parts checker" and a "traffic light".

The objective of the traffic light assignment is to give the students the ability to program and use sequencers in conjunction with operator interface data entry and data read capabilities. The minimum requirements are specified by the section titled background/sequence information. The open-ended nature of the project is tied to the effort made to make the operator interface user friendly. The quality and quantity of the documentation is also open-ended and allows for creativity and critical thinking.

\section{Conclusion}

Feedback from industries indicate that there are competency gaps in graduating engineers particularly in the soft skills areas such as communication skills, team skills, critical thinking skills, and leadership skills. Engineering institutions have made curricular changes to include these skills at different levels with emphasis placed on the senior design project courses. This 
paper has presented a method of including communication and team skills in the lab section of junior level engineering courses by implementing an industrial setting in the labs.

In the industrial setting, the students function as project engineers reporting to the faculty who serves the role of a project manager. Written communications between the engineers and the manager follow an industry type format which uses a two component structure, namely, the executive summary and the discussion. Oral communications focuses on interaction amongst the team members and with the project manager. The team skills for the students are developed by providing them an introduction to issues such as team norms and expectations, project planning using timelines, scheduling of formal team meetings, and an understanding of personality differences.

The projects assigned, typically, have minimum outcomes that are expected upon completion. Additional work involving critical thinking skills is expected to be put forth towards the project if the teams seek to gain a superior performance evaluation (and therefore a high grade). Evaluation of the teams and the team members are done using both objective and subjective measures.

Two examples of projects assigned to students from courses that employ an industrial setting in the labs are presented. Students are provided with the technical fundamentals in the first part of the course before implementing the industrial setting. In the industrial setting the faculty take the approach of a busy project manager thereby expecting the engineers (the students) to be more self reliant by using their critical thinking and problem solving skills.

No academic assessment of the effectiveness of this approach has been implemented yet. But the following observations have been made. Students working in teams in an industrial setting during their junior year are better prepared for the more rigorous senior design projects sequence where they are involved in multi-disciplinary teams working on projects solicited from industry. Through this method of instruction the graduating engineers gain a sound knowledge and appreciation of the soft skills as demanded by the employers. Lastly, oral and written feedback from alumni have indicated this methodology was extremely beneficial in their transition from academia to the work place.

\section{References}

1. Manufacturing Education Plan (Phase I Report): Industry Identifies Competency Gaps Among Newly Hired Engineering Graduates, published by the Society of Manufacturing Engineers, Oct. 1997.

2. Przirembel and E.G. Christian, "Integrating the Product Realization Process into the Undergraduate Curriculum,” ASME Publications, New York, 1995.

3. Report on Surveys of Opinions by Engineering Deans and Employers of Engineering Graduates on the First Professional Degree, NSPE Publication No. 3059, Nov. 1992.

4. Workplace Basics: The Skills Employers Want, American Society for Training and Development and US Department of Labor, Employment and Training Administration, 1988.

5. James Braham, “Employers Demand New Skills,” Machine Design, September 24, 1992.

6. Duesing, P., J. Devaprasad, A. Mahajan, D. McDonald, “Integrating Soft Skillls; A Key Factor in the University to Work Transition," ABET Annual Conference Proceedings, Nov. 1996. 
7. Waitz, I.A. and C.B. Barrett, "Integrated Teaching of Experimental and Communications Skills to Undergraduate Aerospace Engineering Students," ASEE Journal of Engineering Education, Vol. 86, No.3, July 1997.

8. Baren, R. and F.J. Sullivan, "Simulating the Workplace in an Engineering Technology Course: A Rhetorical Model," ASEE Journal of Engineering Education, Vol. 86, No.3, July 1997.

\section{Biographical Information}

JIM DEVAPRASAD is an Associate Professor in the School of Engineering and Technology at LSSU and serves as the chair of the Manufacturing Engineering Technology department. Robotics, automation and control systems are his areas of interest for teaching and applied research. He is actively involved with the Society of Manufacturing Engineers who recognized him with the Outstanding Young Manufacturing Engineering award in 1998.

RAY ADAMS is an Associate Professor and Dean of the College of Engineering, Mathematics, and Business. He received a BS in Engineering Science (1975) and a MS in Mathematics (1978) from Nicholls State University. He has over twenty years of teaching and administration experience. Teaching interests include mechanics of materials, fluid mechanics, and thermodynamics. He is a member of ASEE and ASME.

PAUL DUESING is an associate professor in the School of Engineering and Engineering Technology at Lake Superior State University. He is a licensed engineer in Michigan and is currently Chair of Mechanical Engineering at Lake Superior State University. Previous experience includes working at Procter and Gamble in process development and teaching at the USAF Academy

DAVID MCDONALD is a Professor in the School of Engineering and Technology at Lake Superior State University. He is Chair of the Department of General Engineering and Engineering Technology, and teaches courses in Electrical Engineering and Engineering Technology. His primary interests are in control systems, data acquisition, and modern instrumentation.

MORRIE WALWORTH obtained his BS and MS degrees in Electrical Engineering from Michigan Technological University. He has worked at Lawrence Livermore National Laboratory, Purdue University, and is now the Chair of the Electrical \& Computer Engineering at Lake Superior State University. Professor Walworth is active in research at LSSU and serves as a consultant for Siemens Automotive. 